\title{
Stimulating Conscious Development Mechanism for Movement in Engineering Education
}

\author{
By Rosalie Van Baest*
}

The research is in line with a vision in our society that regards learning as a lifelong process that is not limited to education, it is an ongoing process in which a person is able to direct his own learning. Reflection and awareness are basic conditions in this process. The emphasis is on an intra-personal approach. The practical, exploratory and participatory research takes place in the context of Higher Engineering education which is often cognitive and practical oriented. Affective education is of significance in a process of conscious personal development. Self-reporting provides an insight into the subjective experience of students. The nature of exploratory research is that no strictly predetermined route can be followed by the researcher. Coming to conscious personal development is not a self-evident process. The following key question has therefore been formulated: "How" can one stimulate Higher Engineering students to open up for conscious intra-personal development?". The research resulted in the formulation of the S.C.D. model (Stimulating Conscious Development). (In Dutch: B.O.S. model). The S.C.D. model consists of two parts. The Preliminary research; a field experiment: the SCS module (Social and Communicative Skills), an experiential, student-centered lecture series. The objective of the SCS module is to stimulate Higher Engineering students to open up for conscious personal development. Gaining insight into interpersonal relationships is also of importance in the SCS module, related to effective teamwork. During the SCS process the Research terms were set down. They are the basic assumptions for the next part; a case study: a small-scale, in -depth study which includes three interviews, each time with ten Higher Engineering students, spread over a longer educational period. The case study focuses on the perspective of the research students, who participated voluntary and outside school hours in a positive way, in the research. Handling the method of approach of the S.C.D. model offers a possibility to stimulate Higher Engineering students to open up for personal development.

Keywords: Conscious, Experiential, Intra-Personal Development, Openness, Reflection.

\section{Introduction}

The context of the research is a practical didactic-pedagogical project in Higher Engineering education, that is in line with a vision in our society that regards learning as a lifelong process that is not limited to education, but is a continual process in which people are capable of directing their own learning (Zhao and Biesta 2012). Reflection and awareness are basic conditions in this process. The emphasis is on an intrapersonal approach. The importance of being open to personal development and consciously making personal choices

"Lecturer Social and Communicative Skills, Fontys Hogescholen Engineering, The Netherlands. 
is further underscored by societal developments that occur in increasingly rapid succession and the availability of an unprecedented volume of information.

In the 1990s, there was an urgent appeal from the business sector to the Higher Engineering and Technology education sector, to devote more attention to social and communicative skills in the curriculum, related to the development of personal qualities. Insight into one's personal qualities and those of others is valuable not just to a person's self, but is also a condition for effective teamwork and leadership. Working in groups becomes a focus area in the Engineering and Technology curriculum. At the same time, opportunities to encourage students to devote energy to develop self-knowledge are explored, the starting point of the research.

The quest for possibilities to encourage the personal development of Higher Engineering students, and to develop an insight into the perspective of students as a researcher, go hand in hand. The research can be viewed as a problem analysis that searches for the "knowing how" to create a possibility to stimulate Higher Engineering students in respect of their conscious personal development.

It is not always straightforward for (in this article Higher Engineering) students to motivate themselves in respect of their conscious personal development. The following key question was therefore formulated: are there possibilities to stimulate Higher Engineering students to consciously develop their personal qualities?

There are two underlying presuppositions.

1. People are interpretive beings, if possible, they attach significant meaning to their environment. They want to be recognised as subjects and not approached as objects. In the first place, this implies an intrapersonal approach (Weick 1979).

2. People perform in a specific situation and are influenced by it. They get to know themselves through interaction with others within a specific context. This implies an interpersonal approach.

Focus on the intra-personal is essential for stimulating conscious personal development. In addition to the conscious development of self-knowledge, it is important to learn from interaction with others to thus expand one's selfknowledge. A quest for the path to internalisation is essential. The way in which this quest is shaped could then be of crucial importance.

Learning about one's personal style of learning offers a perspective on learning. Self-guided learning is essential in learning to learn and lifelong learning. The role of lecturers is of significance in the learning process of students.

\section{Conceptual Framework}

The practical research was started out and executed from a social constructivist perspective. 
Everyone is constantly busy "making sense" of their environment. Enactment is the active process by which people view the world with an open mind and thus produce something new. Insight into the process followed is gained retrospectively (Weick 1979). To enable insight into the personal development of and for Mechanical Engineering students, the researcher tries to step into the shoes of the actors, as it were. This entails an intra-personal approach. The attitude and communication style of the researcher influences the attitude and communication of the students. From a social constructivist perspective, knowledge and insight are the result of communicative interaction between individuals.

\section{Exploratory Research}

The research process is a practical, exploratory and participatory process in Higher Engineering education. The nature of an exploratory research study means that the researcher can follow no strictly predetermined route.

The researcher's educational vision is strongly related to Kolb's experiential learning style, which focuses primarily on intra-personal development. According to Kolb, learning is the creation of knowledge through experience. It is not a linear process. Completing Kolb's learning cycle takes place at an abstract level: consciously reflecting on one's own learning at a meta-level. It is a holistic and cyclical learning process. The experientialoriented lecturer has an essential role to play in Kolb's theory. (Kolb and Kolb 2005).

"When it is used in the simple, straightforward, and open way intended, The LSI usually provides valuable self-examination and discussion that recognizes the uniqueness, complexity, and variability in individual approaches to learning. The danger lies in the reification of learning styles into fixed traits, such that learning styles become stereotypes used to pigeonhole individuals and their behaviour." (Kolb 1981-2005).

\section{Methodological Framework}

The practical research sought to identify the "knowing how": how is a possibility created to stimulate the conscious personal development of Engineering students? (Problem analysis).

The basic assumptions of the research are: working on the basis of an appreciative approach, the research takes place with those involved. The research is a means of learning, of looking for a connection between the content and the form of the research. The research adheres closely to the research practice and is directed towards change. It consists of two parts: a Field experiment (preliminary research) and a Case study.

In Preliminary Research, a Field experiment is carried out. The term refers to the method of data collection. The Field experiment describes and interprets the process side of a learning process in a Higher Engineering 
educational context: the development of the SCS module (Social and Communicative Skills) (In Dutch: SCV) in relation to the development of personal qualities. During the Field experiment, the researcher develops a certain insight into the perspective of Higher Engineering students on their personal development. The description of the SCS module is supplemented with quotes from Mechanical Engineering students (Van Baest 2016). SCS teachers also have a learning process during the development of the SCS module. The researcher gave experientially oriented SCS lectures to six lecturers to share practical experience of the SCS module. Explicit designation of the Research terms takes place in Part 1.

In the Case study, a small-scale, in-depth study is conducted in relation to the research terms. This part contains three individual interviews, each time with ten research students, spread over a longer period of time, to enable an insight into personal development within the context of their study programme. The three interviews are qualitative, semi-structured, in-depth interviews based on predetermined topic lists. The underlying question is always: what significance attach the research students themselves to their personal development during their studies?

The data for the practical research are generated in two ways:

- The development and design of the SCS module generates data that contributes to the "knowing how" of the practical research.

- Generate data via self-reporting in both parts offers an insight into the subjective experience for and of those involved. Some quotes of students are included in the article.

\section{Practical Research}

Preliminary Research: Module Social and Communicative Skills in Higher Engineering Education (SCS)

\section{Framework}

"The stimulation of new educational concepts better suited to our multidisciplinary society demands a dynamic setting that is difficult to predefine in literature. Which educational methodology is most appropriate for stimulating the desired learning process? How do people learn self-management? How do you facilitate reflection? Which learning processes ensure that people become more motivated? These learning processes involve behavioural change, personal development and emotions. Changing concepts and visions require more than just the ability to reproduce existing knowledge. These types of change processes are far more complex than traditional knowledge transfer" (Shulman 2006).

The experiential SCS module is part of the foundation course of the Higher Engineering education programme (1998 to 2006). The introduction 
of the concept of teamwork to Higher Engineering education requires the commitment of Engineering students, in terms of developing teamwork skills. For this to happen, conscious reflection on personal attributes is important, in order to gain an insight into oneself, as well as an insight into the attributes of team members. The focus during the SCS module is on intra-personal development, teamwork skills also get attention.

Receptiveness to personal development is not straightforward in the context of Higher Engineering education. Therefore, an entirely different approach was chosen for the SCS module. An essential aspect of the approach to the SCS module comes forward by using experiential stimuli: Engineering students identify which emotions, related to a personal quality, they experience during the experiential SCS assignments (Kolb and Kolb 2005). The students cannot connect these stimuli directly to their Engineering studies. It offers the opportunity to step back from the usual elements of their technological studies.

The interaction between continually changing participants through the years in an educational context, creates different situations continually. The experientially oriented SCS module aims to give Engineering students the possibility to make independent choices in carrying out assignments that focus on the development of personal qualities in the environment in which they find themselves. Each SCS lecture focuses on a different theme that is related to a personal attribute. SCS themes include, amongst others: selfesteem, ambition, resilience to stress, capacity to motivate and to encourage, integrity, responsibility, creativity (Gramsbergen-Hoogland et al. 2005). During the SCS lecture students are exposed to an unexpected experience related to the relevant SCS theme of that lecture, so that the experience will better take root. It is meaningful for the students to be aware of the way in which their personal attributes get across to other students during the SCS lecture. It is also important to demonstrate a willingness to discuss and reflect on their personal attributes. What are the thoughts, emotions, ideas about their behaviour during the SCS lecture and how do they respond to feedback from fellow students?

The freedom to act autonomous as a student during SCS lectures is essential to stimulate Engineering students to take action on their personal development (Rogers 1979). They can make personal choices while carrying out SCS tasks and they can also make personal choices in terms of the approach to their reflective practice (Zhao and Biesta 2012). The SCS module offers the opportunity to engage in a cyclical learning process.

It is of great importance for the SCS lecturer to have a flexible mindset. The attitude and communicative style of the SCS lecturer forms part of the methodology of this research. The process of personal experience and development of SCS skills takes a number of years for the SCS lecturer.

During the period 1998-2006 the lecturer-researcher copied the reflections and evaluations of the SCS module of Mechanical Engineering students out of a positive approach (Seligman and Csikszentmihalyi 2000). This provides a basis for improving the SCS lectures. The reflections and evaluations identify which 
stimuli are effective and which are not, so changes can be made in SCS lectures in the future.

\section{SCS Module in Practice in Higher Engineering Education}

The SCS module is included in the foundation course of the Higher Engineering education programme thanks to a new vision for Engineering education. All SCS lecturers have a great deal of freedom in developing the new module.

- During SCS lectures, Engineering students are continually exposed to new experiences related to personal attributes. They reflect on these experiences through writing a reflective piece in order to expand their ability for self-reflection and to gain new insights into themselves (Giddens 1991).

- The SCS module is primarily focused on intra-personal development and the quest for internal reflection (Kolb and Kolb 2005). The module is focused on the affective development of Engineering students (Goleman 1999).

- Interpersonal skills are also of importance: sharing collective experiences to reflect on personal behaviour and attitude, and to learn from the behaviour and attitudes of fellow students.

- The shared SCS experiences are relevant to all team members, in the context of team building during project work. The SCS learning experience also offers the opportunity to get to know fellow students better on a personal level. In this respect, take part as a team in SCS lectures is essential.

- The continual recurring reflections in the reflective pieces of the students (Giddens 1991) connects the SCS lectures. That means that the SCS module offers the opportunity to engage in a cyclical learning process: after every lecture, students reflect on their learning experience and write a reflective piece of the lecture. At the end of the module, students reflect on the entire SCS module and summarise their thoughts, vision and ideas of the SCS lectures. They note what they regard as positive and negative points of the SCS module. Recurring themes in the reflections of the Mechanical Engineering students form a common thread that links the SCS lectures to one another. Substantiating ideas and opinions in the reflections is an important element during the SCS module. By writing a reflection after every lecture and an evaluation after every SCS period, students are encouraged to reflect consciously on their views of the SCS module and to substantiate these views (Bolin et al. 2005). Students are invited to engage actively in self-reflection (Masui and De Corte 2005).

- Each student participates in the SCS module from the perspective of his/her own personal background and is given the opportunity to follow his/her individual development path within a safe environment. 
Student - I found it incredibly useful to complete this workbook. It is a good way of reflecting on how people are communicative and social beings in practice. Besides, it is fun to work on it in class, knowing that there is a purpose behind it.

Student - I found PCS really helpful to do, particularly writing pieces in the workbook. What you learn in the lectures through tasks, is reflected in the workbook. It makes you reflect more deeply on certain things. (PCS is another name for SCS).

Student - It was actually good to write all those pieces in the workbook. It made me see the world in a different way.

The ability to reflect consciously, to take a step back and think about an experience consciously, is essential for the learning process of development of self-awareness: gaining an insight into oneself, an insight into personal strengths and weaknesses that emerge from behaviour and attitude demonstrated in the SCS lecture (Denton 2011).

Student - In my opinion, SCS is not like traditional learning. They enable you to reflect on things on which you normally would not. This increases your self-awareness. And this self-awareness may, for example, enable you to behave differently in certain situations.

Student - By having to write a page every week about subjects related to communication, you are forced to look at yourself. You become more aware about what you think about certain things and how you perceive things. I enjoyed the lectures and that had a positive effect on the learning process.

During the SCS module it is not the intention to teach students a number of tricks, but to encourage them to reflect, to make them aware of their social and communicative skills in relation to their personal attributes. SCS is about stimulating developing self-awareness, reflecting on individual roles, and acquiring experience and knowledge about the personal attributes of fellow students within the context of SCS. Self-awareness and an insight into personal attributes are not achieved without effort.

It is important, for students as well as for the SCS lecturer, to gain collective experience during the SCS lecture to get insight in different approaches of the SCS assignments. The issue is always whether the stimuli offered, are motivating enough to adopt a personal approach in completing the assignments. The element of surprise is relevant in SCS lectures. A number of assignments were included in the SCS module for a long time.

For example the collective completion of Kolb's learning style test provides a collective learning experience during the SCS lecture. Students discover and identify their personal learning styles. Collectively completing and developing the learning style test makes it possible to gain a sense of the personal learning style, an intra-personal process, and to get to know the learning styles of fellow students, interpersonal (Kyprianidou et al. 2012). Feedback on the interpretation of the learning style test by the SCS lecturer is 
crucial. If the learning style test is only completed once during the study programme, no internalisation of one's personal learning style takes place (Kolb and Kolb 2005).

The SCS lecture series progresses well if Engineering students are receptive to the methodology of the SCS module. This means: students have a flexible attitude and engage actively in SCS lectures. They subsequently carry out a reflection exercise according to their own insights, which they write down in a reflective piece in their workbook. Some students find it very difficult to get used to this style of teaching and reflection: they require more time and space. In addition to receptiveness for their own insights, the students develop receptiveness for their fellow students. The shared learning experience provided by SCS lectures and the insights that are developed as a result, may provide a positive contribution to an enjoyable teamwork experience during the projects.

The book "Personal Quality" (Gramsbergen-Hoogland et al. 2005) offers theoretical support for subjects related to the SCS module.

Self-reporting in the SCS part of the research provides an insight into the subjective experience of Engineering students. A number of terms (Research terms) are highlighted implicitly in the students' reflections and evaluations. The concept of "independence" does not come to the fore in the students" reflections. However, independent (autonomous) functioning is essential and a starting point in SCS lectures. The SCS lecturer stimulates autonomous behaviour and choices from the students (Sousa et al. 2012).

Subjects related to the Research terms which come to the fore in the students' reflections and evaluations (self-reporting) are: contemplation (related to reflection), self-knowledge, motivation (Ryan and Deci 2000) and humour:

Student - In a fun way, you discover, indeed you suddenly realise, what is important in our society. That is the fun part, you suddenly acquire that knowledge, which is not theoretical, but has to be transferred.

Student - I hope that more similar subjects will be offered over the coming years, of which we learn in an enjoyable way and we are not always dealing with material that needs to be processed, but with other things too.

Student - With the greatest of ease, we learn to communicate well, which I think is a really good approach".

and development:

Student - I think that in future, everyone will benefit from the SCS lectures we received. You learn to reflect on your actions, which is always good for personal development.

Student - Usually, you do those things unconsciously, but the SCS lectures teach you awareness. Once you are aware, you are sometimes able to respond better to certain situations".

In addition to experience and theoretical knowledge of SCS themes, a focus on the personal development of young people and a good atmosphere 
(Seligman and Csikszentmihalyi 2000) during the SCS lectures is especially important for the SCS lecturer. The role and attitude of the lecturer during the SCS lectures is crucial for the progression of the SCS lectures. Stimulate to open up for conscious personal development is the essence of the SCS module.

\section{Research Terms}

"Knowing about" does not automatically lead to "knowing how", certainly not when it comes to stimulating personal development. During the SCS process the Research terms were set down. The Research terms consist of: Keywords and Core Values. The "knowing how" of the Keywords and Core Values are connected to one another.

- The Keywords are: self-knowledge, autonomy (Swaine 2012), wellbeing (Seligman and Csikszentmihalyi 2000, Vergeer 2001) and intrinsic motivation (Ryan and Deci. 2000) in relation to personal development.

- The Core Values are: security and trust, space and time, flexibility, simplicity, humour and learning through play. They are expressed in the attitude and communication style of the SCV lecturer.

In the scope of this research a great deal of research is conducted around the "knowing about" of the Keywords and far less around the "knowing how" of the Keywords. Little research was conducted around the "knowing about" and "knowing how" of the Core Values. The Keywords are related to one another and are connected to the process of personal learning and development that takes place during (Higher Engineering and Technology) education. The set down of the Core Values is supported by the reflections and evaluations of the Engineering students during the SCS module. The Core Values are developed from an intra-personal perspective by the lecturer-researcher. They form the basis upon which the SCS lecturer shapes the SCS lectures in his own way.

Consciously choosing a method of communication contributes to the progression of communication in an educational context. The following characteristics of dialogue can be recognised in the SCS module: equality, mutual trust, mutual respect, mutual openness and mutual understanding (Smaling 2008). Consciously applying a specific method of communication does not happen automatically. The objective of an appreciative attitude and the establishment of an equal dialogue with students is to give students as much freedom as possible to make their own decisions and to stimulate them in terms of personal development within the context of SCS. The way in which a SCS lecturer gives feedback has an influence on the lectures. 


\section{Case Study}

During the learning process of the lecturer-researcher in the preliminary research, the Field experiment, a need for a deeper insight into the intrinsic motivation and personal development of Engineering students originated (Sousa et al. 2012). The idea came into being that stimulating the conscious personal development of students during their Engineering studies requires more time and space, than given to the SCS module in the curriculum, to make individual students aware of the growth and development of their personal qualities.

The Case study focuses on the perspective of ten research students, who participated voluntary and outside school hours in the research. This offers the opportunity to generate data about the subjective experience of ten Mechanical Engineering students in relation to their studies during the research period. The Keywords form recurring discussion points during the individual interviews. The Core Values guide the researcher's communication and attitude.

In the Case study three individual interviews, with each research student, were carried out during a longer period of education. A number of personal stories are important for gaining a deeper understanding of personal development and they offer an opportunity for the research students to internalise aspects of their personal development.

The Core Values provide a basis for the communication and the attitude of the researcher during the interviews. The atmosphere during the interviews determines the progression of the interviews. In addition to the characteristics of dialogue, the characteristics of critical dialogue: argumentative character, reflective character, evaluative character, cooperative character and mutual favourable interpretation (Smaling 2008) are applied and stimulated.

During the interviews the research students were given the freedom and time to express their own individual values and stories: their narratives (Basten 2010). By communicating their personal values and stories in relation to the Keywords, the research students can get to know their personal reality, related to their study, in a conscious way (Zhao and Biesta 2012). Repetition makes internalisation of one's self-image possible.

Before the interviews takes place topic lists were composed. They provide a framework for the interviews, but also allow scope for personal stories. In addition to discussing the Keywords, each interview also covers "other" topics to promote the playful character of the interviews and to encourage openness and spontaneous responses from the students, for example the pop-up book "Journal des inventions de Leonard da Vinci" (Da Vinci 2008).

The interviews demonstrate the research students' openness to selfknowledge and the importance they attach to acquire and develop selfknowledge.

Each research student demonstrates his own paradigm, his own subjective perspective (Barker 1996). Conscious reflection plays an essential role in the process of conscious development. 
At the end of the third interview each of the ten research students gave his opinion about the experience with the research (self-reporting). Every research student has a pseudonym to protect their privacy.

Beethoven. "I think it also gives a good look of who you are yourself. By thinking about the questions you asked. Yes, I do think indeed that it is for yourself ..." .

Jesse. "It was not obligatory. It was completely without obligations. I liked to do it, everything that is written on paper was said. It was always funny to read it back at home. To see yourself a bit on paper. Yes, very funny. I also let my parents read it sometimes and they really had something like: "yes, that fits exactly with you".

"Yes, self-awareness, a little bit. When it is on paper and you read it again sometime, then indeed you have something like: "I have to pay more attention to that, or something like that".

Homer. "It was good. But so those interviews are just right. You can chat a bit. Of course you will think about it for a moment ... Because you bring forward some subjects that you obviously do not speak out by yourself. But really thinking profoundly about it? No, I did not do that. But there are things that you become more aware of".

Dylan. "In itself as pleasant. I especially liked it because where you worry about, what you think, you can express that. I think that's nice about the research. For me personally, I liked it. Maybe a little less as reflection, because I was working on it myself. If I can ever help you or something, then I'd like to hear it. I mean that too. Perhaps my role as a thinker, if you ever want to brainstorm about something, maybe".

Lou. "I learned a lot of it too. Handy to look back on certain things and also to think about it in a different way. Then I think I have benefited from it myself. I don't know what the results are going to be, but ... I first had the idea that my motivation would not change so much in the course of my education. But still you're going in another direction. It has not changed dramatically, but nevertheless it steered towards what I want to do". "There's a lot of change, I did not expect that. When I think back, if I had not participated in that research, then I also would not have thought about that it is changed. Of course about making decisions, but not about that motivation: "What do I want to do?".

"Motivation and looking back at what you have learned and what kind of developments you have gone through ... Technical students, they don't do that much. If you think about it as the group, then it is: "no, we don't do that, we build stuff".

Raven. "Positive. I have also learned a few things myself. You reflect indeed. You say it instead of thinking about it. You can also place yourself, I know what my direction will be ". 
Thor. "Yes, nice, yes. I could help you with it, I think, or not with that research? For myself I have learned a number of things, especially those learning styles and such, I did not know that at first. I did not know those four learning styles. I have something there, also maybe in the future. I gained more knowledge and learned more about myself. So. Yes, that was fun and significant".

Casper. "I liked it. It's very funny, because if you read those interviews again, you realize more how you're put together. And I thought that was really funny. And very interesting. It is a bit awareness. Through such questions and also if you, say you walk out the room after a short while, then it's always ... Then I'm still working on it some time. And actually I think that this is just ... If you could do that for everyone here... Yes, it takes a lot of time, of course ... But it's okay, so to speak. Just simply good about you ... To be able to speak about how you think you are. And what your motivations are. Because it's just very nice to be able to talk to someone about ...".

Django. "Well, I liked to tell a story. I think that at the end of the research I have to put everything together. Then you can see the process a little bit, because that is rather difficult per interview. It is a process and a lot has changed. When it is finished, I want to look at it again and put it one after another".

Sky. "It was fun. There was always interest in what you like and everything. Those qualities and how you experience it here at school. That was nice and the sandwiches of course".

"I think a bit more about how you stand in live, how you look at yourself. That's what it's about for a great deal. That you think more about it. The piece of text of a few moments ago "Passion and intuition" (Goleman, 1999) that stays with me. That it's going that way for myself, also in business."

After recording and analysing the interviews (the final version of the interviews is approved by the research students), the narrative of each research student is told in a new way by the researcher. The items "Selfknowledge", "Learning style" and "Personal development" of each interview, amongst others, feature in the new idea. The voice of the narrator is part of a greater community, in this case Higher Engineering education. That voice is represented by the narratives of the research students.

\section{Review}

The practical research ultimately resulted in the formulation of the S.C.D. model: the Stimulating Conscious Development model (In Dutch: B.O.S. model). The S.C.D. model consists of two parts. 
The first focuses on openness and stimulating the personal development of (Mechanical Engineering) students.

The second comprises three interviews, in each case with ten research students, spread over a longer period of education to facilitate internalisation of the Keywords. The interviews focus on the individual, personal development of students in an educational context.

Use of the approach of the S.C.D. model offers a possibility to stimulate Mechanical Engineering students to be open to personal development. The methodology applied offers guidelines for a potential strategy within an educational framework and calls for further research.

To develop an insight into the subjects: intra-personal development, reflection, Kolb's learning style, self-knowledge, autonomy, motivation, individual interviews and the learning process of personal development, was of critical importance for the research and contributed to the explicit definition of the research terms.

\section{Conclusions}

Conclusions related to the methodology of the S.C.D. model applied in Higher Engineering education:

- In the curriculum of Higher Engineering education a process of conscious personal development of students has to be given time and space from the start of the first year of an academic study.

- The S.C.D. model (affective education) is embedded in the curriculum of Higher Engineering education and is related to some of the other (technical or practical) modules.

- The emphasis on stimulating the process of conscious personal development of students lies in the first year of study.

- Experiential learning in the SCS module, that is related with the process of intra-personal and interpersonal learning, is introduced in the curriculum at the start of the first year of an academic study. Students can experience the personal qualities of themselves and of their fellow students, which can support teamwork in engineering projects. Communication about the experiences with all the participants and feedback on the experiences is essential.

- Introduction of a reflection notebook to write down the SCS reflections and evaluations: a way to keep the reflections and evaluations together. This gives the opportunity for each student to read the reflections and evaluations again and notice possible changes in their personal development and their way of thinking.

- Continually stimulating openness to personal development makes internalisation of self-knowledge possible.

- The role of the SCS lecturer is of the greatest importance in the S.C.D. model. Therefore the lecturer must have the opportunity to experience a SCS learning process himself (or herself) to gain insight into the 
conscious personal learning process of him/herself, as well as of the students in Higher Engineering education.

\section{Acknowledgments}

This article tells the story of my research "Stimulating Conscious Development. Mechanism for Movement in Engineering Education" (2017). The positive cooperation of the students, especially with the research students, was of vital importance for the research.

\section{References}

Barker J (1996) Paradigma's. Mentale Modellen voor de Toekomst. [Paradigms. Mental Models for the Future]. Scriptum Books.

Basten F (2010) Cursus Narratieve Analyse [Course Narrative Analysis]. (Campus) Orléon.

Bolin AU, Khramtsova I, Saarnio D (2005) Using Student Journals to Stimulate Authentic Learning: Balancing Bloom`s Cognitive and Affective Domains. Teaching of Psychology 32(3): 154-159.

Da Vinci L (2008) Journal des Inventions de Leonard da Vinci. [Working Inventions Leonardo da Vinci]. Larousse.

Denton D (2011) Reflection and Learning: Characteristics, Obstacles, and Implications. Educational Philosophy and Theory 43(8): 838-852.

Giddens A (1991) Modernity and Self-Identity. Stanford University Press.

Goleman D (1999) Emotionele Intelligentie in de Praktijk. [Working with Emotional Intelligence]. Uitgeverij Contact.

Gramsbergen-Hoogland YH, Deveer MAJ, Leezenberg MG (2005) Persoonlijke Kwaliteit. [Personal Quality]. Uitgeverij Wolters Noordhoff.

Kolb A, Kolb D (2005) The Kolb Learning Style Inventory-Version 3.1. 2005 Technical Specifications. HayGroup. LSI Technical Manual.

Kyprianidou M, Demetriadis S, Tsiatsos T, Pombortsis A (2012) Group Formation based on Learning Styles: Can it Improve Students` Teamwork? Education Technical Research Development 60: 83-110.

Masui C, De Corte E (2005) Learning to Reflect and to Attribute Constructively as Basic Components of Self-Regulated Learning. British Journal of Educational Psychology 75: 351-372.

Rogers C (1979) Leren in Vrijheid. [Freedom to Learn]. Uitgeverij De Toorts.

Ryan R, Deci E (2000) Intrinsic and Extrinsic Motivations: Classic Definitions and New Directions. Contemporary Educational Psychology 25: 54-67.

Seligman M, Csikszentmihalyi M (2000) Positive Psychology, An Introduction. American Psychologist 55(1): 5-14.

Shulman LS (2006) Lectoraat Pedagogiek van de Beroepsvorming van de Haagse Hogeschool/TH Rijswijk Koninklijke De Swart, Den Haag 1-244.

Smaling A (2008) Begrijp ik u Goed? Dialoog en Empathie in de Methodologie. Verslag van het Afscheidssymposium van Adri Smaling. [Do I Understand you Well? Dialogue and Empathy in Methodology. Report of the Farewell Symposium of Adri Smaling. Anke Snoek Kwalon 13, 3. Boom Amsterdam. 
Sousa C, Coelho F, Guillamon-Saorin E (2012) Personal Values, Autonomy, and SelfEfficacy: Evidence from Frontline Service Employees. International Journal of Selection and Assessment 20(2): 159-170.

Swaine L (2012) The False Right to Autonomy in Education. Educational Theory 62(1): 107-124.

Van Baest R (2016) SCS (Social and Communication Skills). International Symposium on Project Approaches in Engineering Education. Volume 6(2016).

Vergeer F (2001) Autonomie en Welbevinden. [Autonomy and Well-being]. Proefschrift (PhD) Katholieke Universiteit Nijmegen.

Weick KE (1979) The Social Psychology of Organizing. Organiseren volgens Weick.pdf-Arno Korsten.

Zhao K, Biesta G (2012) The Moral Dimension of Lifelong Learning: Giddens, Taylor, and the "Reflexive Project of the Self". Adult Education Quarterly 62(4): 332350 . 
